\title{
THE TREATMENT OF TUBERCULOUS PLEURISY
}

\author{
BY \\ PAUL FORGACS \\ From Queen Mary's Hospital, Sidcup
}

(RECEIVED FOR PUBLICATION MAY 20, 1957)

The object of treatment in tuberculous pleurisy is to shorten the acute phase of the illness, to restore the integrity of the pleura, and, above all, to prevent further manifestations of tuberculosis. Rest, chemotherapy, and aspiration are each supposed to achieve some of these aims, but their relative importance has not been established. The value of rest was stressed by Roper and Waring (1955), chemotherapy received particular attention from Emerson (1955) and from Falk and Stead (1956), while Mackay-Dick and Rothnie (1954) dealt mainly with the results of early aspiration.

These three components of treatment were subjected to a controlled trial at Queen Mary's Hospital, Sidcup. The results to be presented are based on the progress of 169 patients treated during 1952-4 and kept under observation for two years.

\section{DEsign of the Trial}

The plan of treatment ensured that approximately half the patients received antituberculosis drugs, while the remaining patients were treated by rest alone. Within the latter group the orthodox sanatorium régime was compared with a considerably shortened form of treatment by rest, from which the period spent on graduated activity and convalescence had been omitted. Early and delayed aspiration, practised alternately within each group, divided the patients into two further series of approximately equal size.

The method of treatment was chosen by random allocation of numbers 1-4 in combination with letters A or B to each patient on admission. The number indicated the details of general treatment, while the letter determined the management of the effusion on the following lines:

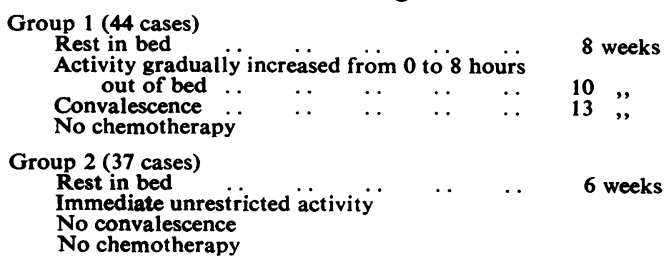

Group 3 (41 cases). Same régime as Group 2 Chemotherapy for 60 daysStreptomycin, 1 g. daily Sodium $p$-aminosalicylate (P.A.S.), 18 g. daily

Group 4 (47 cases). Same régime as Group 2 Chemotherapy for 60 days-

Streptomycin, $1 \mathrm{~g}$. twice weekly Isoniazid, $200 \mathrm{mg}$. daily

In each of these groups two alternative methods were used for dealing with the pleural effusion :

Group A (90 cases)

Early and intensive aspiration

Breathing exercises from the start

Group B (79 cases)

Aspiration, if necessary, at 6 weeks

Breathing exercises started at 6 weeks

For reasons to be explained later, it was found possible to merge Group 1 with Group 2 and Group 3 with Group 4, in comparing the results of rest alone with those of rest and chemotherapy. These combined groups were designated by letters $R$ (rest) and $C$ (chemotherapy).

Group R (81 cases). Groups 1 and 2 combined Group C (88 cases). Groups 3 and 4 combined

\section{Diagnostic Criteria}

Every patient admitted between August, 1952, and July, 1954, with a unilateral tuberculous pleural effusion, uncomplicated by any other manifestation of tuberculosis, was included in the trial. The diagnosis was proved by culture of tubercle bacilli from the effusion in nine cases only. In the remaining patients the diagnosis was based on the clinical features of the disease, occasionally supported by a history of close contact with infectious tuberculosis.

A lymphocytic pleural effusion in tuberculinpositive young adults is likely to be a manifestation of tuberculosis. The only other common variety of serous pleurisy at this age is a complication of pneumonia treated with antibiotics. This type of pleurisy can generally be recognized in retrospect by the history of the presenting symptoms. Tuberculous pleurisy is usually preceded by intermittent pain in one side of the chest for some weeks before the sudden exudation of fluid. Other 
bacterial infections of the pleura do not give such long notice of their approach, and are ushered in by symptoms of an acute respiratory infection. The effusion they produce is smaller, contains a higher proportion of polymorphonuclear cells, and is absorbed more rapidly.

Other varieties of lymphocytic pleurisy may have been admitted to the trial, but they are not likely to have been numerous or unevenly distributed. Comparison of the treatment groups would therefore remain valid in spite of the inherent uncertainty of clinical diagnosis.

\section{ExCLUSIONS}

The number of patients admitted to the trial was 182 , and 13 of these were excluded after treatment had started. The reasons for their exclusion were as follows :

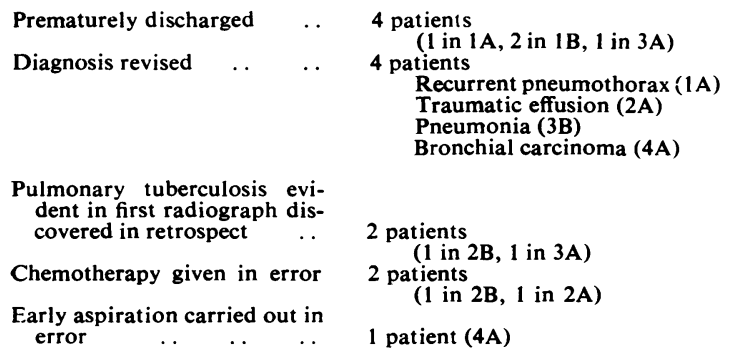

\section{Comparison of Groups at the Start of TREATMENT}

Table I sets out the number of patients remaining in the trial in each of the treatment groups A, B, R, and C, classified according to sex and age. The conventional grouping into five social classes, based on occupation, was replaced by a direct assessment of the housekeeping money and the standard of housing of the patient's family. These data reflect more accurately the standard of nutrition and the extent of overcrowding, two of the most important social factors affecting the progress of a tuberculous patient. Owing to the reticence of some patients, the information on these two points is, however, incomplete.

Clinical findings compared at the start of treatment include the temperature on admission, the initial level of the sedimentation rate, and the maximum size of the pleural effusion. The date of onset of the effusion is often uncertain. When the illness begins acutely, with fever and sudden severe pain, these symptoms usually mark the exudation of fluid. More often an intermittent pain precedes the effusion by some weeks, while in others the collection of fluid is discovered by
TABLE I

COMPARISON OF GROUPS AT THE START OF TREATMENT

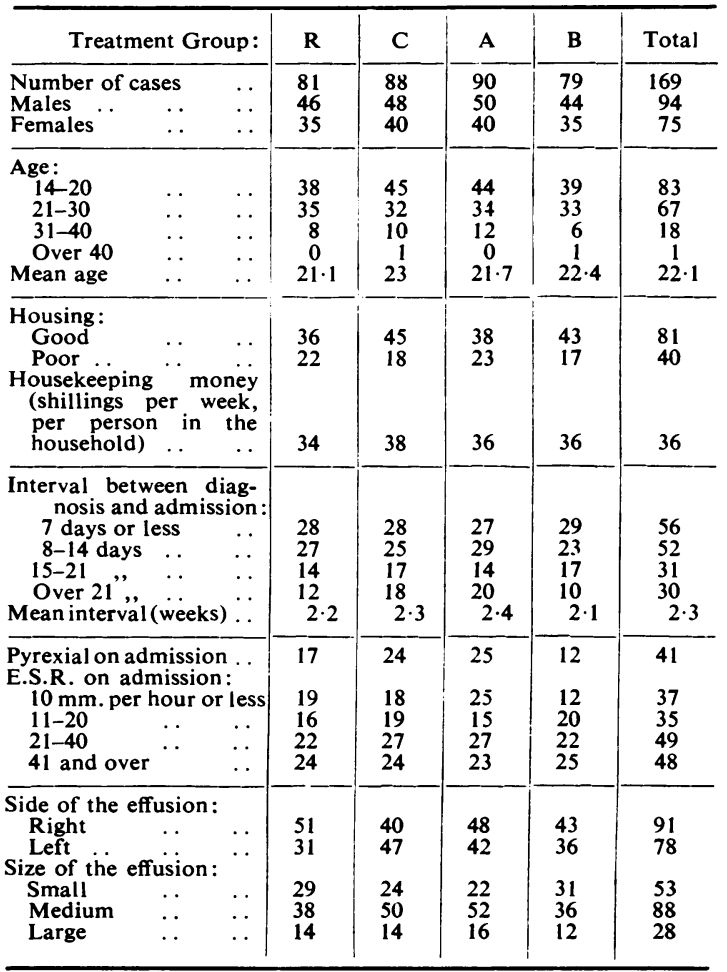

$\mathbf{R}=$ Rest alone. $\mathbf{C}=\mathbf{R e s t}$ and chemotherapy. $\mathbf{A}=$ Early aspiration. $\mathbf{B}=$ Delayed aspiration.

routine radiography. In such circumstances the date of its onset cannot be established. The interval between the date of diagnosis and the date of admission recorded in Table $I$ is therefore only a rough measure of the delay in starting treatment.

\section{METHOD OF Follow-UP}

All patients were still in hospital eight weeks after admission, when their progress was first reviewed. Further information during the first year was obtained by an inquiry addressed to the chest clinics at six months and at 12 months after admission. The progress of all patients was reviewed two years after the last of them had been admitted to the trial. This final review was made by personal visits to the chest clinics and consultation with the physicians in charge in rather less than half the series, and by questionnaire in the remaining half. The complete series of radiographs was obtained and reviewed whenever pulmonary complications had been reported. Twelve patients were lost from observation, having ceased to 
attend at their chest clinics within 18 months of admission to hospital. The date of final review in the remaining 157 patients was that of their visit to the clinic nearest to the second anniversary of their admission to hospital. The mean duration of observation of these patients was 24.4 months (S.D. 2.4 months).

One patient died from cerebral haemorrhage 16 months after the pleural effusion. He was known to have had chronic nephritis for at least two years before developing tuberculous pleurisy. At necropsy no evidence of tuberculosis was found.

There were no deaths from tuberculosis.

\section{The EFfect of Rest}

Two groups of patients in this trial were treated by rest alone. Those in Group 1 were kept in bed for eight weeks and then got up by stages over a period of 10 weeks, so that by the end of 18 weeks in hospital they were out of bed for eight hours daily. At this stage they went to a convalescent home for 13 weeks. The total length of their treatment was 31 weeks.

Patients in Group 2 were kept in bed for six weeks and were then allowed up immediately all day. They went home after 10 weeks in hospital, grading and convalescence having been omitted. The total length of their treatment was 10 weeks.

The management of the two groups during the first eight weeks was so similar that a comparison of their progress at the end of this period would be unprofitable. The two régimes began to diverge only during the last fortnight of this period, when patients in Group 1 were still confined to bed while patients in Group 2 were getting up all day. The difference between the physical activity of patients during this fortnight is sufficient to account for the excess of weight gained in eight weeks by patients in Group 1 (11.1 lb. or $5.0 \mathrm{~kg}$.) over those in Group $2(9.4 \mathrm{lb}$. or $4.3 \mathrm{~kg}$.). The sudden transition from complete rest to full activity in Group 2 had no ill effects, judging by the temperature chart, the sedimentation rate, or the incidence of immediate complications. The number of complications diagnosed during the twoyear period after admission to hospital, excluding the first eight weeks, is shown in Table II. There were 10 complications in Group 1 and seven complications in Group 2. Recurrence of the effusion was diagnosed in one patient in Group 1 and in three patients in Group 2. The corresponding figures for primary tuberculous lesions were two and one ; and for dissemination seven in Group 1 and three in Group 2. The higher incidence of
TABLE II

THE EFFECT OF REST BY COMPARISON OF COMPLICATION RATES IN GROUPS 1 AND 2 AT TWO YEARS*

\begin{tabular}{|c|c|c|c|c|c|}
\hline \multicolumn{3}{|c|}{ Treatment Group: } & $\begin{array}{c}1 \\
\text { (44 Cases) }\end{array}$ & $\stackrel{2}{\text { (37 Cases) }}$ & Total \\
\hline $\begin{array}{l}\text { Recurrence of the } \\
\text { Primary lesions .. } \\
\text { Dissemination .. }\end{array}$ & $\begin{array}{l}\text { fusion } \\
\ldots \\
\ldots\end{array}$ & $\begin{array}{l}\ldots \\
\cdots \\
\cdots\end{array}$ & $\begin{array}{l}1 \\
2 \\
7\end{array}$ & $\begin{array}{l}3 \\
1 \\
3\end{array}$ & $\begin{array}{r}4 \\
3 \\
10\end{array}$ \\
\hline All complications & . & . & 10 & 7 & 17 \\
\hline
\end{tabular}

* Complications during the first eight weeks excluded.

Group $1=$ Long rest, graduated activity and convalescence.

Group $2=$ Short rest followed by immediate full activity.

dissemination in the group treated on orthodox sanatorium lines is likely to be due to chance $\left(\chi^{2}=0.54 ; 0.5>P>0.3\right)$.

In the original plan of the trial, patients in Group 2 alone were intended to serve as controls in comparing rest with chemotherapy, because the duration of rest in Groups 2, 3, and 4 was identical. When it was found that the duration of rest did not affect the complication rate, Groups 1 and 2 were combined in Group $R$ (rest) as a single control series.

\section{The Effect of Chemotherapy}

Two groups of patients (Groups 3 and 4) were treated with drugs in addition to rest. Comparison of their progress showed no evidence that one form of chemotherapy was more effective than the other, and the two groups were therefore combined in a single Group C (chemotherapy). Comparison of the progress of Group C with Group $\mathbf{R}$ is presented in Tables III, IV, and V.

Duration of THE FEVER.-The temperature of 128 patients was already normal on admission. Treatment with drugs did not start until the eighth day in hospital, and during the preceding week the temperature of 19 patients settled to normal. There remained a group of 22 patients (10 in

TABLE III

THE EFFECT OF CHEMOTHERAPY AND ASPIRATION BY COMPARISON OF GROUPS R AND C AND GROUPS A

\begin{tabular}{|c|c|c|c|c|c|}
\hline Treatment Group: & $\mathbf{R}$ & C & $\mathbf{A}$ & B & $\underset{\text { Groups }}{\text { All }}$ \\
\hline Gain in weight (lb.) & $10 \cdot 3$ & 7.2 & 8.9 & 8.4 & $8 \cdot 7$ \\
\hline $\begin{array}{l}\text { Sedimentation rate: } \\
\text { No. of cases with } \\
\text { E.S.R. over } 10 \mathrm{~mm} \text {.: } \\
\text { On admission .. } \\
\text { At } 8 \text { weeks } \ldots \\
\text { Rise of E.S.R. by } \\
20 \text { mm. or more } \\
\text { a bove previous } \\
\text { week's level. No. } \\
\text { of cases .. .. }\end{array}$ & $\begin{array}{c}62 \\
20 \\
(32 \%) \\
\\
14 \\
(23 \%)\end{array}$ & $\begin{array}{c}70 \\
29 \\
(42 \%) \\
\\
5 \\
(7 \%)\end{array}$ & $\begin{array}{c}65 \\
23 \\
(35 \%) \\
\\
12 \\
(18 \%)\end{array}$ & $\begin{array}{c}67 \\
26 \\
(38 \%) \\
\\
7 \\
(10 \%)\end{array}$ & $\begin{array}{c}132 \\
49 \\
(37 \%) \\
\\
19 \\
(14 \%)\end{array}$ \\
\hline
\end{tabular}


TABLE IV

THE EFFECT OF CHEMOTHERAPY AND ASPIRATION ON PROGRESS OF EFFUSION ASSESSED AT 8 WEEKS

\begin{tabular}{|c|c|c|c|c|c|c|}
\hline Treatment Grou & up : & $\mathbf{R}$ & C & A & B & $\begin{array}{l}\text { All } \\
\text { roups }\end{array}$ \\
\hline $\begin{array}{l}\text { ize of the effusion } \\
8 \text { weeks (all cases } \\
\text { Clear } \ldots \\
\text { Small } \ldots \\
\text { Moderate } \\
\text { Total no. of cases }\end{array}$ & $\begin{array}{l}\cdots \\
. \\
. \\
. \\
. .\end{array}$ & $\begin{array}{c}55 \\
(68 \%) \\
17 \\
(21 \%) \\
9 \\
(11 \%) \\
81 \\
(100 \%)\end{array}$ & $\begin{array}{c}62 \\
(70 \%) \\
21 \\
(24 \%) \\
5 \% \\
(6 \%) \\
88 \\
(100 \%)\end{array}$ & $\begin{array}{c}61 \\
(68 \%) \\
22 \\
(24 \%) \\
7 \\
(8 \%) \\
90 \\
(100 \%)\end{array}$ & $\begin{array}{c}56 \\
(71 \%) \\
16 \\
(20 \%) \\
7 \% \\
(9 \%) \\
79 \\
(100 \%)\end{array}$ & $\begin{array}{c}117 \\
(69 \%) \\
38 \\
(22 \%) \\
14 \\
(9 \%) \\
169 \\
(100 \%)\end{array}$ \\
\hline $\begin{array}{c}\text { Initially large effusion } \\
\text { Clear } \\
\text { Small } \\
\text { Moderate } \\
\text { Total no. of cases }\end{array}$ & $\begin{array}{c}\text { ns: } \\
. \\
.\end{array}$ & $\begin{array}{c}10 \\
(50 \%) \\
6 \\
(30 \%) \\
4 \\
(20 \%) \\
20 \\
(100 \%)\end{array}$ & $\begin{array}{c}18 \\
(58 \%) \\
9 \\
(29 \%) \\
4 \\
(13 \%) \\
31 \\
(100 \%)\end{array}$ & $\begin{array}{c}17 \\
(59 \%) \\
9 \\
(31 \%) \\
3 \\
(10 \%) \\
29 \\
(100 \%)\end{array}$ & $\begin{array}{c}11 \\
(50 \%) \\
6 \\
(27 \%) \\
5 \\
(23 \%) \\
22 \\
(100 \%)\end{array}$ & $\begin{array}{c}28 \\
(55 \%) \\
15 \\
(29 \%) \\
8 \\
(16 \%) \\
51 \\
(100 \%)\end{array}$ \\
\hline $\begin{array}{l}\text { nitially large effusic } \\
\text { admitted early: } \\
\text { Clear .. } \\
\text { Small .. } \\
\text { Moderate } \\
\text { Total no. of cases }\end{array}$ & .. & $\begin{array}{c}8 \\
(57 \%) \\
5 \\
(36 \%) \\
1 \\
(7 \%) \\
14 \\
(100 \%)\end{array}$ & $\begin{array}{c}7 \\
(58 \%) \\
4 \\
(33 \%) \\
1 \\
(9 \%) \\
12 \\
(100 \%)\end{array}$ & $\begin{array}{c}7 \\
(70 \%) \\
3 \\
(30 \%) \\
0 \\
10 \\
(100 \%)\end{array}$ & $\begin{array}{c}8 \\
(50 \%) \\
6 \\
(38 \%) \\
2 \\
(12 \%) \\
16 \\
(100 \%)\end{array}$ & $\begin{array}{c}15 \\
(57 \%) \\
9 \\
(35 \%) \\
2 \\
(8 \%) \\
26 \\
(100 \%)\end{array}$ \\
\hline
\end{tabular}

TABLE V

EFFECT OF CHEMOTHERAPY AND ASPIRATION ON INCIDENCE OF COMPLICATIONS

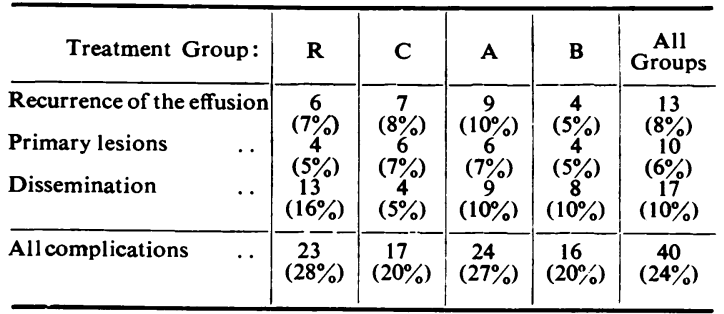

Group $R$ and 12 in Group C) with pyrexia of $99^{\circ} \mathrm{F} .\left(37.2^{\circ}\right.$ C. $)$ or higher at the beginning of the second week. The mean duration of the fever, reckoned from the day of admission in Group $\mathbf{R}$, was 3.9 weeks (S.D. 1.5) and in Group C 2.5 weeks (S.D. 0.55). Chemotherapy may have shortened the pyrexial phase of the illness, but the number of febrile patients was too small for certainty on this point.

The Sedimentation Rate.-The sedimentation rate was estimated by Westergren's method on admission and at weekly intervals during the first eight weeks. The initial E.S.R. reading was above $10 \mathrm{~mm}$. per hour in 132 patients, and in 49 of these it had settled to $10 \mathrm{~mm}$. per hour or less by the end of the eighth week. The corresponding figures in Group $R$ were 62 and $20(32 \%)$, in
Group C 70 and 29 (42\%). The difference between the two groups is not significant (standard error of the difference, $7.3 \%$ ).

When the behaviour of the E.S.R. in patients with initially high readings $(41 \mathrm{~mm}$. per hour or above) is analysed, again no difference is found between the two groups. There were 24 such patients in each group, and the number among them with an E.S.R. of $10 \mathrm{~mm}$. per hour or less at eight weeks was four in Group $R$ and three in Group C.

The E.S.R. readings in tuberculous pleurisy show a steady downward trend week by week, but in some patients this is interrupted by a sharp rise, in the absence of any clinically recognizable complication. Such a rise by more than $20 \mathrm{~mm}$. per hour above the previous week's figure was recorded in $14(23 \%)$ of the 62 cases with an initially raised E.S.R. in Group R, and in five $(7 \%)$ of the 70 cases in Group C. The difference between the incidence of this unexplained finding in the two groups is significant $\left(\chi^{2}=5.1 ; 0.05>\mathrm{P}>0.02\right)$.

GaIN IN WEIGHT.-The average gain in weight during the first eight weeks in Group $\mathbf{R}$ was $10.3 \mathrm{lb}$. (4.7 kg.) and in Group C it was $7.2 \mathrm{lb}$. $(3.4 \mathrm{~kg}$.). The difference may be explained by the excess of weight $(11.1 \mathrm{lb}$. or $5.1 \mathrm{~kg}$.) gained by patients in Group 1, who were kept in bed two weeks longer, and by the small gain $(4.7 \mathrm{lb}$. or $2.1 \mathrm{~kg}$.) by patients in Group 3, who were taking P.A.S. Comparison of Groups 2 and 4 eliminates the difference due to these factors and shows no advantage in the group treated with streptomycin and isoniazid $(9.3 \mathrm{lb}$. or $4.2 \mathrm{~kg}$.) over the group treated by rest alone $(9.4 \mathrm{lb}$. or $4.3 \mathrm{~kg}$.).

Progress of THE Effusion.-The rate of reabsorption of the pleural effusion was not influenced by chemotherapy. A review at eight weeks showed no significant difference between the number of patients in Groups $R$ and $C$ with moderate, small, or no residual collection of fluid in the pleural cavity. Comparison of the progress of 51 patients admitted with effusions extending to the level of the fourth rib or higher, and of 26 patients selected from this group who had large effusions and had come under treatment within four weeks of complaining of pain in the chest, again showed no difference between those treated with and without drugs.

At two years after admission 16 patients (eight in Group $R$ and eight in Group C) were reported to have pleural shadows amounting to more than obliteration of the costophrenic angle.

Tuberculous Complications.-Most of the tuberculous complications of pleurisy follow the 
effusion within two years (Thompson, 1946 ; Wynn-Williams and Shaw, 1955). Their incidence in the present series was therefore estimated at two years after admission. These complications were classified into one of the following three groups :

(a) Recurrence of the Effusion.-The clinical features of this complication are reaccumulation of the pleural exudate on the side of the original effusion after this had partially or completely cleared, fever, rise of the E.S.R., and recurrence of pain in the chest. It is presumably due to reinfection of the pleura from the same source as in the initial attack. Two cases of tuberculous empyema, defined as an effusion containing predominantly polymorphonuclear cells and tubercle bacilli visible on direct smears, were also classified under this heading.

Chemotherapy did not prevent recurrence of the effusion, since of the 13 patients with this complication there were six in Group $\mathrm{R}$ and seven in Group C. It also failed to protect two patients against the gradual transition of a serous effusion into a tuberculous empyema. Both patients who developed this complication had been treated with streptomycin and isoniazid.

(b) Primary Tuberculous Lesions.-This group includes primary foci in the lung, enlarged mediastinal lymph nodes, and the two in combination as a primary complex. Single nodules were assumed to be primary foci wherever situated. While such a classification is likely to be correct when the nodule is in the middle or lower zones of the radiograph, such a shadow in the upper zones may arise from coalescence of scattered micronodular lesions. In the early stages of postprimary tuberculosis the distinction between these lesions and primary foci may not be possible.

Primary tuberculous lesions of the lung developed in 10 patients, of whom four were in Group $R$ and six in Group C. In three of the six patients in Group $C$, the primary lesion appeared within two months of the start of treatment, while they were still receiving chemotherapy. These figures suggest that treatment with drugs at this stage of the infection fails to restrain the progressive enlargement of primary tuberculous lesions.

(c) Dissemination.-All distant manifestations of tuberculosis, such as bone and synovial infections, meningitis, peritonitis, and contralateral pleural effusions, were classified under this heading. This group also includes the micronodular type of apical tuberculosis, whether bilateral or confined to one lung.
Disseminated tuberculous lesions were much less common among patients who had received chemotherapy. Of the 17 patients who developed complications of this type, 13 had been treated by rest alone and only four with drugs $\left(\chi^{2}=5 ; 0.05\right.$ $>\mathrm{P}>0.02$ ). The types and numbers of complications in the two groups were: contralateral effusions four and one ; apical pulmonary tuberculosis five and two; and extrathoracic infections four and one. Extrathoracic tuberculosis includes one case each of meningitis, tenosynovitis of the hand, and caries of the spine, and two cases of peritonitis.

\section{The Effect of Aspiration}

Conclusions about the effect of aspiration were based upon a comparison of the progress of patients in Group A with those in Group B (Tables III, IV, and V). In Group A the effusion was aspirated on admission and on alternate days subsequently, until no more fluid could be withdrawn. As much fluid as possible was removed on each occasion. Breathing exercises were given from the start. In Group B only a sample of fluid was taken on admission and evacuation was not attempted until six weeks later. Breathing exercises were started at the beginning of the seventh week.

Duration of the Fever.-Early aspiration did not shorten the pyrexial stage of the illness. Its mean length in 26 patients, pyrexial on admission and treated in Group A, was two weeks (S.D. 1.2), and in 15 patients pyrexial on admission and treated in Group B it was 2.4 weeks (S.D. 1.9), reckoned from the day of admission.

The Erythrocyte Sedimentation Rate (E.S.R.).-Patients with E.S.R. readings above $10 \mathrm{~mm}$. per hour by the Westergren method on admission were about evenly divided between Group A (65 cases) and Group B (67 cases). The rate of decline of the E.S.R. was not influenced by aspiration. At the end of eight weeks $23(35 \%)$ of these patients in Group A and $26(38 \%)$ in Group B had E.S.R. readings of $10 \mathrm{~mm}$. per hour or lower.

The sedimentation rate rose by more than 20 $\mathrm{mm}$. per hour above the previous week's level in 19 patients. Of these, 12 patients $(18 \%)$ were in Group A and seven (10\%) in Group B. The uneven distribution was probably due to chance (standard error of the difference, $10 \%$ ).

GaIN IN WeIGHT.-There was no significant difference between the average gain in weight at eight weeks in Group A (8.9 lb. or $4.1 \mathrm{~kg}$.) and Group B (8.4 lb. or $3.8 \mathrm{~kg}$.). 
Progress of the Effusion.-The tendency of serous tuberculous effusions towards spontaneous absorption is illustrated by the complete clearing of the fluid at eight weeks after admission in 117 $(69 \%)$ of the 169 patients in the trial. At this stage no patient had a large effusion, and only 14 $(9 \%)$ were left with an effusion of moderate size.

There is no evidence to show that early and repeated aspiration played any part in bringing about such a favourable outcome. The proportion of patients with moderate, small, and completely absorbed effusions at eight weeks was similar in the two groups.

In order to avoid dilution of these figures by the large number of initially small effusions, the progress of patients admitted with effusions extending to the level of the fourth rib or higher was separately analysed. There were 51 such patients : 29 in Group A and 22 in Group B. Of these, eight were left with effusions of moderate size at the end of eight weeks in Group $A$ and five in Group B.

The uncertainty about the date of onset of the effusion is a particularly serious drawback in comparing two methods of treatment, which differed only in respect of the timing of the aspiration. An attempt was made to overcome this difficulty by selecting from the 51 patients admitted with large effusions those who experienced pain in the chest for the first time not more than four weeks before admission. There were only 26 patients who satisfied this condition: 10 in Group $A$ and 16 in Group B. Comparison of their state at eight weeks favours the group treated by early aspiration, but the difference is not significant.

Two years after admission there were 16 patients with pleural thickening amounting to more than obliteration of the costophrenic angle. Of these, six had been treated in Group $A$ and 10 in Group B.

Diaphragmatic Movement and Chest ExpanSION.-A classification of the various grades of restricted diaphragmatic excursion proved to be unreliable in practice, because the shadow of the effusion interfered with accurate measurement. A record was, however, kept of the number of patients in each group whose diaphragm was immobilized or moved paradoxically at eight weeks after admission. Unilateral restriction of chest expansion was also difficult to measure, so that only the most severe grades of immobilization were recorded.

Chest movements were still severely restricted at eight weeks in 21 patients, 12 in Group $A$ and nine in Group B. Diaphragmatic excursion was absent or paradoxical in 26 patients, 16 in Group $A$ and 10 in Group B. The only patient for whom excision of the pleura was performed, on account of postural deformity and loss of chest movement at 16 months after admission, had been treated by early aspiration.

Tuberculous Complications.-Aspiration had no effect on the incidence of complications. $\mathrm{Re}$ currence of the effusion was more common in the group treated by early aspiration than in the group treated conservatively, nine patients $(10 \%)$ in Group A and four patients (5\%) in Group B ; but such a small difference is likely to be due to chance $\left(\chi^{2}=0.82 ; 0.5>P>0.3\right)$. Both patients who developed tuberculous empyema had been treated by early aspiration. The change from serous to purulent effusion was discovered four months after admission in one patient and seven months after admission in the other.

The difference between the number of primary tuberculous lesions was even smaller, six cases in Group A and four cases in Group B. Complications due to dissemination were evenly divided between the two groups.

Complications Due to Aspiration.-Two patients, one in each group, developed a pneumothorax as a result of aspiration. Discomfort was a common complaint after the evacuation of large effusions, but this procedure had no other ill effect.

\section{Discussion}

The results of this trial show that, among the three components of treatment, chemotherapy alone has an appreciable effect upon the course and complications of tuberculous pleurisy. Even chemotherapy lacks the clear-cut and immediate effect observed in other acute forms of tuberculosis. By present standards drugs were given for too short a period and one of the combinations would be regarded to-day as ill-advised. In 1952, when the trial was planned, such short courses of chemotherapy were, however, in common use, and the relative inefficacy of the intermittent administration of streptomycin with daily isoniazid in preventing the emergence of resistant strains was not appreciated. It is therefore possible that, if treatment with drugs had been continued longer, more patients might have been saved from the late sequelae of tuberculous pleurisy. In the dosage prescribed during this trial, drugs certainly reduce the risk of dissemination and may shorten the duration of the fever. They do not hasten the clearing of the effusion or lessen the danger 
of its recurrence, and they fail to restrain the development of progressive primary tuberculous lesions.

The effect of chemotherapy on the sedimentation rate is more ambiguous. This test is generally regarded as a guide to the activity of tuberculous processes, but its significance in tuberculous pleurisy is by no means clear. The tuberculous lesion responsible for the infection of the pleura is usually concealed from observation and its progress cannot be compared with the behaviour of the sedimentation rate. In chemically induced inflammations of the pleura, as in tuberculous pleurisy, it follows closely the development and clearing of the effusion. It seems likely therefore that the sedimentation rate reflects the progress of the inflammation of the pleura rather than that of an underlying tuberculous infection. The rate of improvement of the E.S.R. and the inflammation it reflects are both unaffected by treatment.

When the steady downward trend of the sedimentation rate is interrupted by a sharp rise, and this coincides with a recurrence of the effusion or some other complication, the explanation is obvious. No complication, however, accompanied such a rise of the E.S.R. in 19 patients, of whom 14 had been treated by rest alone and only five by chemotherapy. The success of chemotherapy in preventing this unexplained rise of the sedimentation rate suggests that the rise may have been due to a clinically silent dissemination of tubercle bacilli.

Our findings are in general agreement with those of Emerson (1955), who compared the progress of 25 patients treated with streptomycin and P.A.S. with 40 patients treated by rest alone. Of these, 19 patients in the chemotherapy group and 32 in the control group had pleural effusions uncomplicated by pulmonary lesions. He found that chemotherapy shortened the duration of the fever and considerably reduced the incidence of tuberculous complications. His conclusions agree with ours that chemotherapy does not hasten the reabsorption of the effusion or the return of the sedimentation rate to a normal level. The results of a co-operative trial organized by the U.S. Veterans Administration and reported by Falk and Stead (1956) confirm the value of chemotherapy in the prevention of complications.

The principle of encouraging early re-expansion of the lung is universally accepted when the pleural cavity contains a collection of blood, pus, or air. The indifferent results of early aspiration in speeding functional recovery and clearing of tuberculous effusion were therefore unexpected.
The explanation lies in the greater tendency of tuberculous serous effusions towards spontaneous absorption, so that the results of conservative management were equally favourable.

While the early aspiration of tuberculous effusions may be justified by theoretical arguments, if not by practical results, there are neither theoretical nor practical reasons for the attempted removal of fluid remaining in the pleural cavity after a lapse of several weeks. At this stage the effusion is contained in a rigid compartment, bounded on both sides by thickened pleura, so that paracentesis yields only small quantities of fluid before the procedure becomes uncomfortable. In such circumstances the effusion reaccumulates soon after aspiration. The progress of patients in this trial did not support the belief that aspiration at this stage encourages the spontaneous reabsorption of a hitherto stationary collection of fluid.

In contrast to the generally favourable outcome of the effusion, there is occasionally severe deformity and loss of chest expansion resulting from constrictive pleurisy. Such functional disasters occur only after large effusions, but even among these they are uncommon, and cannot be foreseen in the early stages of the disease. The treatment of this condition is excision of the fibrosed pleura, but the decision to operate should not be taken prematurely. Clearing of the pleural shadow and recovery of function continue for as long as two years, and it is reasonable to wait while there is progressive improvement.

The effect of early and intensive aspiration on the rate of clearing of the pleural shadow was investigated by Mackay-Dick and Rothnie (1954). They compared 140 patients treated conservatively with 50 patients treated by intensive aspiration and early breathing exercises, combined with systemic and intrapleural chemotherapy. The rate of absorption of moderate and small effusions was similar in the two groups. Among 33 large effusions, treated conservatively, 15 were unresolved at 12 months and three at 24 months, while 10 similar effusions treated by aspiration had all resolved by the end of nine months. These findings are open to the criticism that the control series was not treated concurrently, and that the 190 patients presented for comparison were selected from a larger series of 250 patients.

Prolonged rest in the treatment of tuberculous pleurisy is widely prescribed, but the belief in its efficacy is based on general principles rather than on experimental evidence. Controlled trials to test its value have not been undertaken, and the opportunity for such trials is passing, now that 
chemotherapy is in general use. The results of this trial suggest that, so far as the incidence of tuberculous complications is concerned, the traditional sanatorium routine has no advantage over a considerably shortened form of treatment by rest.

A retrospective assessment of the value of rest in tuberculous pleurisy led Mitchell (1953) to a similar conclusion, though he points out that the duration of rest prescribed in his series may have been adjusted to the severity of the illness. Without more precise information on this point, it is not possible to judge how far these two factors operating in opposite directions may have counteracted one another.

The findings of Roper and Waring (1955), on the other hand, show a striking correlation between the duration of rest in bed and the incidence of complications. Their conclusions are based on a five-year period of observation of 178 young men serving in the army of the United States. The complication and relapse rate of $61 \%$ over the whole series, and of $30 \%$ among patients kept at rest for at least six months, is, however, far higher than anything recorded among civilians or Service personnel in this country.

The principles of management of tuberculous pleurisy may be stated briefly in conclusion. Chemotherapy is by far the most important ingredient of treatment and should always be prescribed in order to prevent dissemination of tubercle bacilli. Confinement to bed for six weeks is probably long enough for uncomplicated pleurisy. Graded return to full activity and a long stay in a sanatorium has no demonstrable advantages and should be reserved for patients whose standard of living is low. The effusion may be aspirated for sampling, to correct displacement of the mediastinum, and to relieve discomfort, but is not effective in speeding functional recovery.

\section{SUMMARY}

The effect of rest, chemotherapy, and early aspiration in tuberculous pleurisy was studied by a controlled trial on 169 patients, kept under observation for two years.

Of these three components of treatment only chemotherapy influenced the course of the disease. Its most important effect is the prevention of complications due to dissemination of tubercle bacilli. Chemotherapy probably shortens the pyrexial stage of the illness, but does not hasten reabsorption of the effusion. It exercises no control over the development of the primary complex and fails to prevent reinfection of the pleura.

Early and intensive aspiration has no advantage over the conservative management of the effusion.

The incidence of complications among patients treated by rest alone was not affected by omitting the period of graduated exercise and convalescence.

I am indebted to the house physicians and nursing staff of Queen Mary's Hospital, to whose duties this trial added an appreciable burden; to Dr. C. E. Bell and Dr. Elaine Gilbert for their help in keeping the records; to Mr. E. S. Beauchamp and his clerical staff for assistance in following up the progress of these patients; and to my colleagues in charge of chest clinics, too numerous to mention by name, for the trouble they have taken in answering my inquiries.

\section{REFERENCES}

Emerson, P. A. (1955). Quart. J. Med., 24, 61.

Falk, A., and Stead, W. W. (1956). Amer. Rev. Tuberc., 74, 897. Mackay-Dick, J., and Rothnie, N. G. (1954). Tubercle (Lond.), 35. 182.

Mitchell, R. S. (1953). Amer. Rev. Tuberc., 67, 421

Roper, W. H., and Waring, J. J. (1955). Ibid., 71, 616.

Thompson, B. C. (1946). Ibid., 54, 349.

Wynn-Williams, N., and Shaw, J. B. (1955). Tubercle (Lont.), 36, 74. 